\title{
SISTEM INFORMASI KOPERASI KARYAWAN PADA PT. ANUGERAH PHARMINDO LESTARI BERBASIS JARINGAN
}

\author{
Ita Arfyanti $^{1 \text {, }}$, Siti Lailiyah ${ }^{2)}$, Astika Erwin Putranto ${ }^{3)}$ \\ ${ }^{1,3}$ Sistem Informasi, STMIK Widya Cipta Dharma \\ ${ }^{2}$ Teknik Informatika, STMIK Widya Cipta Dharma \\ Jl. M. Yamin No. 25, Samarinda, 75123 \\ E-mail : qonita23@yahoo.com ${ }^{1)}$, lail.59a@gmail.com ${ }^{2)}$, ashdutz@gmail.com ${ }^{3)}$
}

\begin{abstract}
ABSTRAK
Tujuan dari penelitian sistem informasi Koperasi Karyawan untuk mempermudah para pegawai koperasi dalam menyajikan informasi kepada para anggota koperasi dalam hal jual beli barang maupun simpan pinjam anggota koperasi.

Metode Penelitian yang digunakan pada penelitian ini meliputin Studi Lapangan yang terdiri dari wawancara terhadap salah satu pegawai koperasi dan Observasi langsung ke tempat penelitian, Studi Pustaka yaitu peneliti mengambil beberapa wacana dari Pustaka yang digunakan untuk memperkuat metode penelitian. Metode Pengembangan Sistem yang digunakan di dalam penelitian ini menggunakan metode Waterfall, dimana tahap pengembangannya terdiri dari : Requirement Definition, System and Software Design, Implementation and Unit Testing, Integration and System Testing dan Operation and Maintenance.
\end{abstract}

Hasil yang diharapkan oleh peneliti adalah Sistem Informasi Koperasi yang tepat guna dan tepat sasaran, mudah digunakan oleh para karyawan koperasi maupun anggota koperasi.

Kata Kunci : Sistem, Informasi, Sistem Informasi, Koperasi, SHU

\section{PENDAhuluan}

Memasuki era perdagangan bebas yang sangat pesat seperti sekarang ini, para pelaku ekonomi dituntut harus selalu aktif dan memiliki inovasi dalam mengembangkan usaha yang dimilikinya, agar usaha yang telah dibangunnya dapat menjadi semakin berkembang. Sekarang ini banyak pedagang kecil yang baru merintis usahanya dengan modal yang kecil. Untuk dapat mendirikan usaha yang dapat memenuhi kebutuhan konsumen, diperlukan modal yang cukup besar agar usahanya dapat semakin berkembang.

Pada Koperasi Karyawan "PT. A P L", juga terdapat pelayanan Simpan Pinjam dan Jual Beli. Sistem pencatatan administrasi di Koperasi Karyawan "PT. A P L" masih menggunakan buku besar yang kemudian ke excel. Kelemahan sistem disana pencatatan data-data transaksinya masih manual, sehingga tidak efisien. Setiap melakukan transaksi petugas harus memasukkan data pribadi anggota. Model pembuatan laporan itu sering mengakibatkan terjadinya kesalahan. Petugas juga kesulitan membuat rincian sesuai dengan kebutuhan.

Dari latar belakang masalah yang ada maka peneliti memberikan solusi kepada koperasi untuk membuat suatu sistem informasi koperasi karyawan yang cepat, akurat, update, dan juga mudah oleh para karyawan koperasi maupun anggota koperasi.
2. RUANG LINGKUP PENELITIAN

Permasalahan difokuskan kepada :

1. Perhitungan SHU yang terdapat di dalam koperasi

2. Perhitungan didapatkan dari transaksi anggota koperasi, simpan pinjam, dan laba dari perusahaan

3. Perhitungan SHU yang mudah, cepat dan akurat yang diperoleh dari proses transaksi anggota koperasi, simpan pinjam dan laba perusahaan

\section{BAHAN DAN METODE}

\subsection{Koperasi}

Koperasi adalah organisasi ekonomi rakyat yang berwatak sosial, beranggotakan orang-orang atau badan hukum yang merupakan tata susunan ekonomi sebagai usaha bersama berdasarkan asas kekeluargaan (Hendrojogi, 2004).

\subsection{Flow of Document}

Flow of Document adalah suatu model bagan alur untuk menggambarkan sistem dokumen dari proses pelaporan yang dapat dihubungkan satu sama yang lain dengan alur data, baik secara manual maupun terkomputerisasi (Jogiyanto, 2008). 
Tabel 1. Simbol Flow of Document

\begin{tabular}{|c|c|}
\hline SIMBOL & KETERANGAN \\
\hline & $\begin{array}{l}\text { Titik terminal, digunakan } \\
\text { untuk menunjukkan proses } \\
\text { awal dan akhir dari suatu } \\
\text { proses }\end{array}$ \\
\hline & Operasi secara manual \\
\hline & $\begin{array}{l}\text { Fungsi pengelolahan proses } \\
\text { /menunjukkan kegiatan proses } \\
\text { program komputer }\end{array}$ \\
\hline & $\begin{array}{l}\text { Simbol Input/output, } \\
\text { digunakan untuk mewakili } \\
\text { data input/output }\end{array}$ \\
\hline & $\begin{array}{l}\text { Dokumen atau laporan input } \\
\text { output baik untuk proses } \\
\text { manual, mekanik atau }\end{array}$ \\
\hline & $\begin{array}{l}\text { Menunjukkan } \\
\text { menggunakan }\end{array}$ \\
\hline & $\begin{array}{l}\text { Tempat Penyimpanan Data } \\
\text { Menggunakan Hard Disk }\end{array}$ \\
\hline & $\begin{array}{l}\text { Arus Informasi / } \text { kegiatan } \\
\text { proses dari operasi } \\
\text { komprogram } \\
\text { komprer }\end{array}$ \\
\hline & $\begin{array}{l}\text { File storage offline } \\
\text { Numeric, Character }\end{array}$ \\
\hline & $\begin{array}{l}\text { Penghubung kehalaman yang } \\
\text { masih sama / kehalaman yang }\end{array}$ \\
\hline
\end{tabular}

\subsection{Model Air Terjun}

Model ini adalah model klasik yang bersifat sistematis dan berurutan dalam membangun software (Simarmata, 2010).

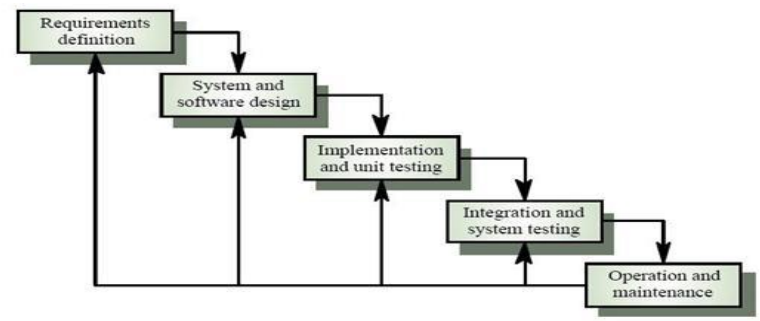

Gambar 1. Fase-fase dalam Waterfall Model

\section{RANCANGAN SISTEM INFORMASI}

1. Flow of Document yang berjalan

FOD yang berjalan yang terdapat di dalam PT. Anugerah Pharmindo Lestari. Dimulai dari anggota mengisi slip setoran, slip setoran yang sudah terisi kemudian diserahkan kepada kasir, dari kasir memproses angsuran kredit anggota hingga menjadi bukti slip setoran dan kwitansi yang diserahkan kepada anggota. Kasir membuat laporan data anggota, angsuran dan pinjaman untuk diserahkan kepada pimpinan.

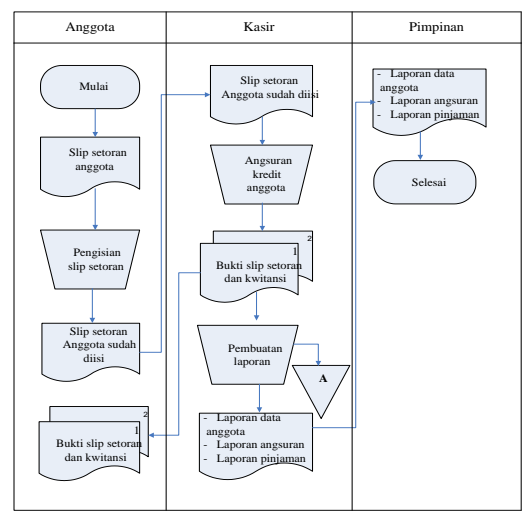

Gambar 2. Flow of Document yang sedang berjalan

\section{Flow of Document yang diusulkan}

Bagian admin telah menginputkan data-data anggota, data anggaran dasar, data distributor, data barang kedalam sistem dan disimpan kedalam database. Proses dimulai saat anggota datang ke koperasi dan memberikan data anggota kepada bagian admin. Bagian admin menginputkan data anggota koperasi tersebut kedalam sistem database. Anggota yang sudah mendaftar menerima kartu anggota. Jika anggota koperasi tersebut melakukan transaksi pembelian barang maka bagian kasir akan menginputkan data penjualan barang dan kemudian masuk ke system database, dan anggota tersebut mendapat bukti pembelian barang. Anggota koperasi yang melakukan transaksi simpan pinjam langsung menuju ke bag. Simpan Pinjam, bag. Simpan pinjam menginputkan apa yang dilakukan anggota koperasi tersebut. Dari proses inputan tersebut menghasilkan nota simpanan maupun pinjaman yang diberikan kepada anggota koperasi sebagi bukti. Anggota yang melakukan pembayaran angsuran mendapatkan bukti nota angsuran dari bag. Simpan pinjam. 


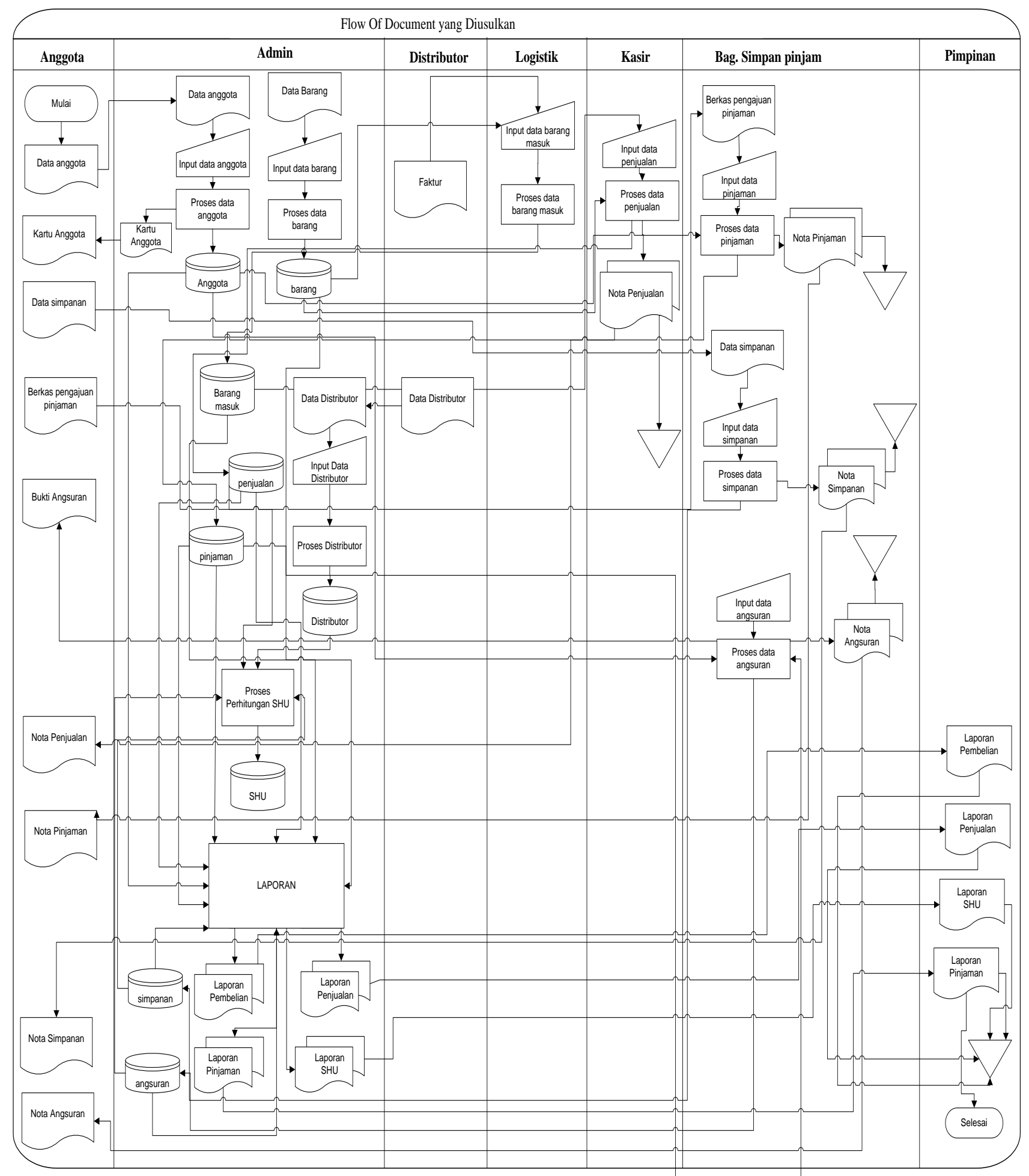

Gambar 3. Flow of Document yang diusulkan

\section{Context Diagram}

Terdapat entitas anggota yang memberikan data anggota, berkas pengajuan pinjaman dan mendapatkan kartu anggota, nota penjualan, nota simpanan, nota pinjaman dan nota angsuran. Entitas logistik memberikan data barang masuk. Entitas admin memberikan data barang dan juga menerima laporan dari system. Entitas kasir yang memberikan data penjualan dan juga nota penjualan. Entitas bag. Simpan pinjam yang memberikan data simpanan, pinjaman, angsuran dan nota simpanan, pinjaman dan angsuran. Entitas distributor yang memberikan data distributor dan faktur. Yang terakhir entitas pimpinan yang menerima laporan dari sistem 


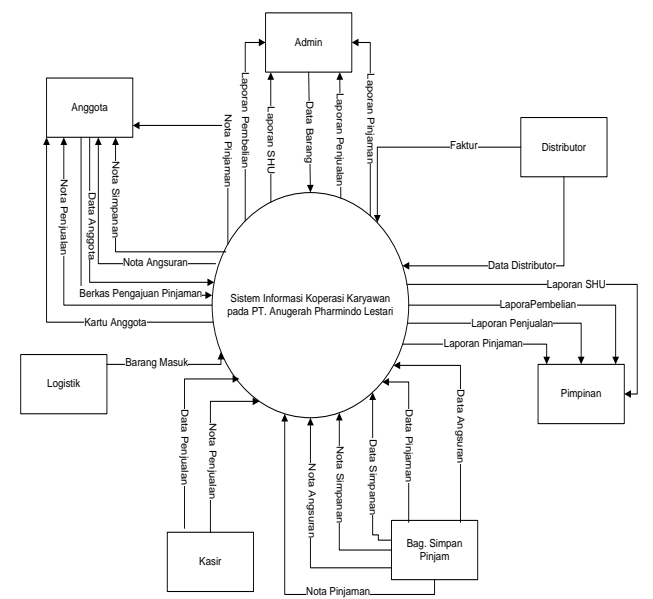

Gambar 4. Context Diagram

4. Data Flow Diagram Level 0

Terdapat tujuh entitas yaitu anggota, distributor, logistic, kasir, admin, bag. Simpan pinjam dan pimpinan. Proses pertama dimulai dengan entitas anggota menginputkan data anggota yang disimpan kedalam data store anggota. Dari data store anggota tersebut anggota mendapatkan kartu anggota. Entitas distributor menginputkan data distributor yang disimpan kedalam data store distributor. Entitas logistic menginputkan data pembelian barang yang disimpan ke dalam data store pembelian. Entitas kasir menginputkan data penjualan yang disimpan ke dalam data store penjualan. Jikan anggota koperasi melakukan transaksi pembelian barang, mendapatkan nota penjualan yang didapatkan dari data store penjualan dan anggota. Entitas admin yang menginputkan data barang, anggaran dasar yang disimpan ke dalam data store barang dan anggaran dasar. Proses simpanan, pinjaman dan angsuran yang dilakukan oleh anggota koperasi disimpan ke data store simpanan, pinjaman dan angsuran, dan anggota koperasi mendapatkan nota simpanan, pinjaman dan angsuran dari masing-masing data store. Dan proses SHU anggota koperasi juga diinputkan oleh admin dan disimpan ke data store SHU. Proses ini melibatkan tabel simpanan, pinjaman, angsuran, penjualan, dan anggota. Entitas pimpinan menerima laporan pembelian yang melibatkan tabel pembelian, kemudian laporan penjualan melibatkan tabel penjualan, laporan SHU yang melibatkan tabel pinjaman, angsuran, simpanan, penjualan, dan anggota dan laporan pinjaman yang melibatkan tabel pinjaman.

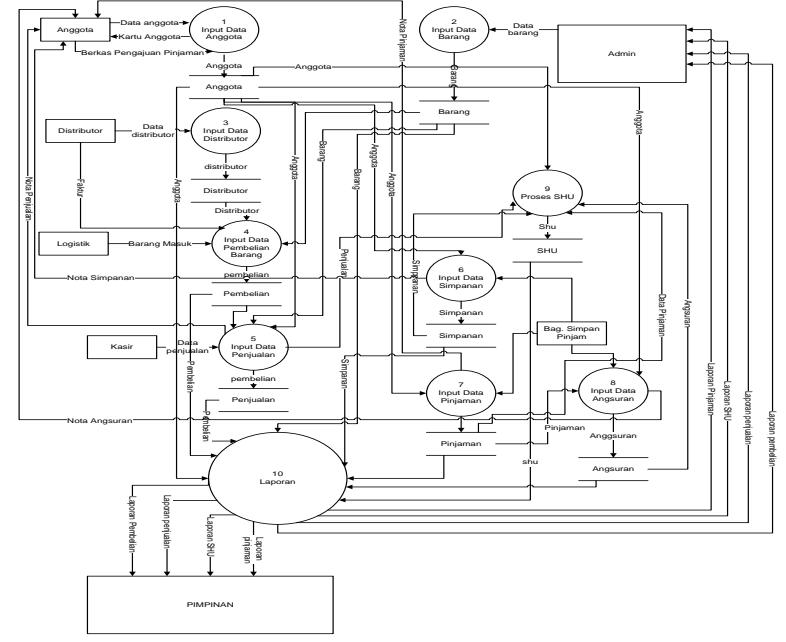

Gambar 5. Data Flow Diagram Level 0

5. Data Flow Diagram Level 1 pada proses laporan

Laporan pembelian didapatkan dari data store distributor dan barang. Laporan penjualan didapatkan dari data store anggota, barang dan penjualan. Laporan pinjaman didapatkan dari data store anggota dan pinjaman. Laporan SHU didapatkan dari data store anggota, pembelian, angsuran dan SHU. Laporan tersebut diberikan kepada admin dan juga pimpinan koperasi

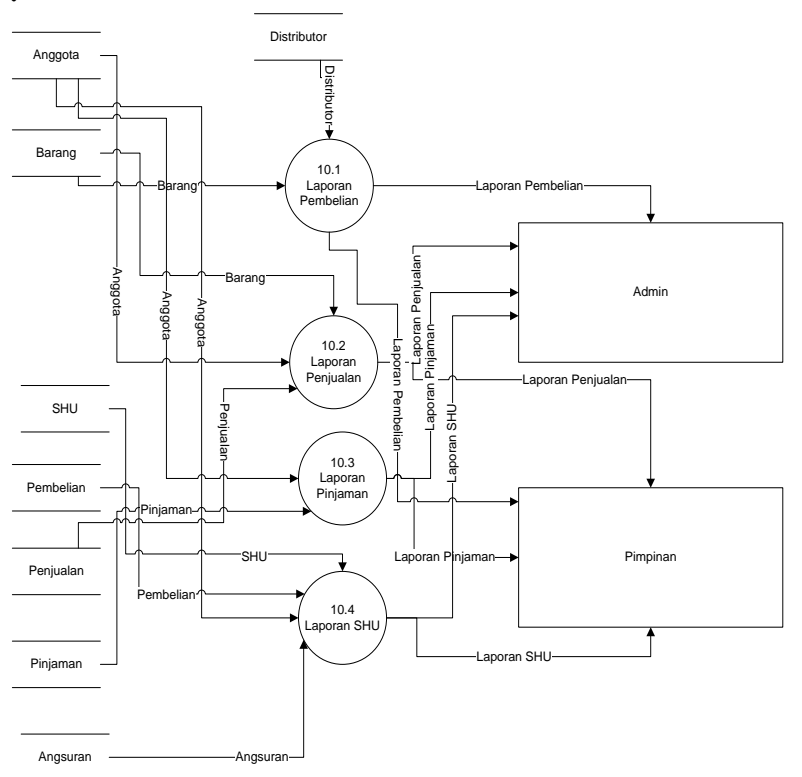

Gambar 6. Data Flow Diagram Level 1 pada proses laporan

6. Hierarchy Input Process Output

Adapun diagram Hierarchy Input Process Output (HIPO) dari Sistem Informasi Koperasi Karyawan "PT. A P L" dapat dilihat pada gambar 7. 


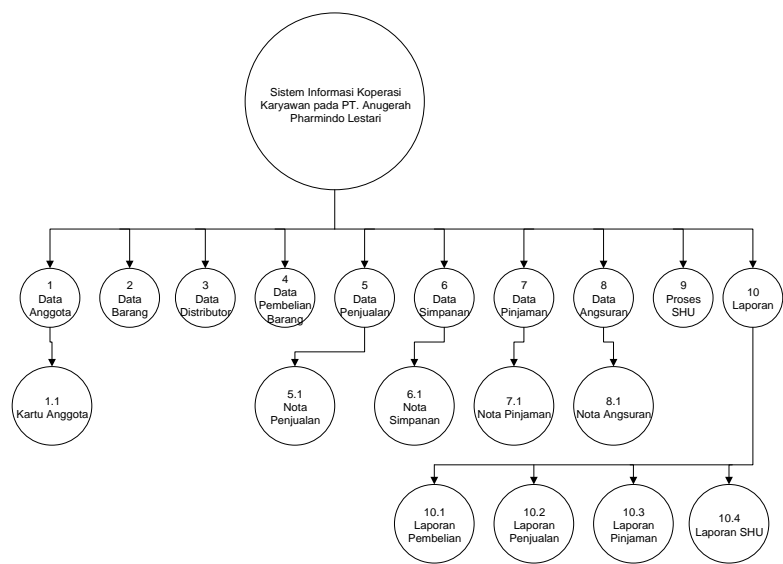

Gambar 7. Hierarchy Input Process Output

7. Relasi antar Tabel

Relasi antar tabel digunakan untuk mempermudah hubungan antar entitas yang satu dengan entitas yang lain sehinga mempermudah sistem kerja antar entitas.

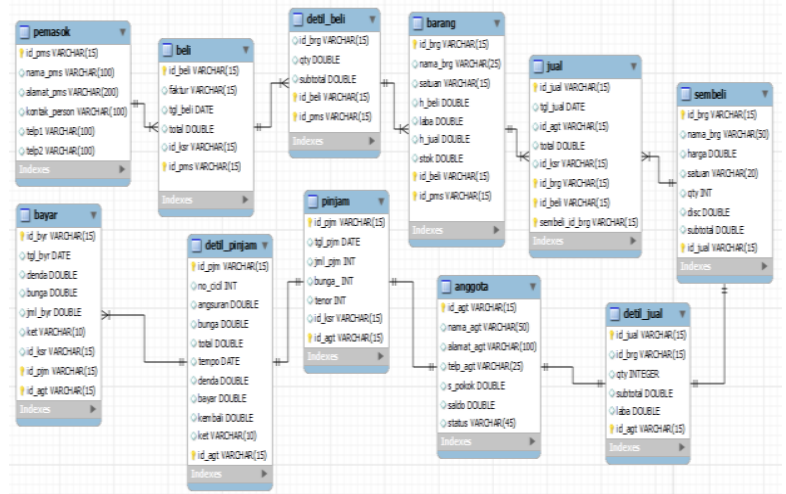

Gambar 8. Relasi Antar Tabel

\section{IMPLEMENTASI}

1. Microsoft Visual Basic 6.0

Microsoft visual basic adalah bahasa pemrograman yang memiliki IDE (Integrated Development Environtment) digunakan untuk membuat aplikasi windows yang berbasis grafis (GUI - Graphical User Interface) (Mangkulo, 2003).

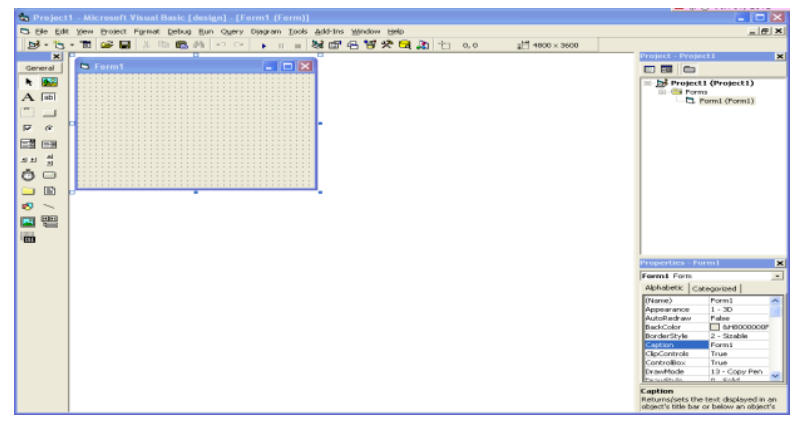

Gambar 9. Tampilan Microsoft Visual Basic 6.0

\section{Seagate Crystal Report 8.5}

Crystal Report adalah suatu program aplikasi untuk pembuatan laporan atau report yang sangat canggih serta mudah dalam penggunaanya. Selain itu, Crystal Report dapat menggunakan berbagai Format data dari berbagai program aplikasi. Sumber data yang dapat dipakai dengan program aplikasi ini dapat berasal dari data lokal maupun sumber data remote, misalnya dari komputer server (Hadi, 2003).

Crystal Report adalah suatu program aplikasi untuk membuat laporan-laporan dalam berbagai bentuk dan dari berbagai sumber data (Alam, 2005)

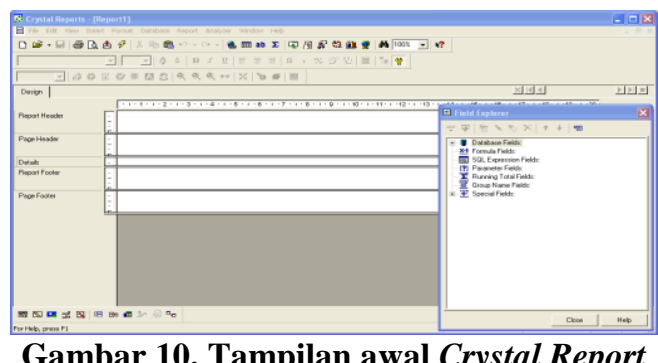

3. MySQL

salah satu aplikasi database yang cukup di kenal adalah MySql yang mana merupakan suatu aplikasi database server yang dapat menangani data bervolume besar. MySql adalah program database yang mampu mengirim dan menerima data dengan sangat cepat dan multiuser (Kadir, 2008).

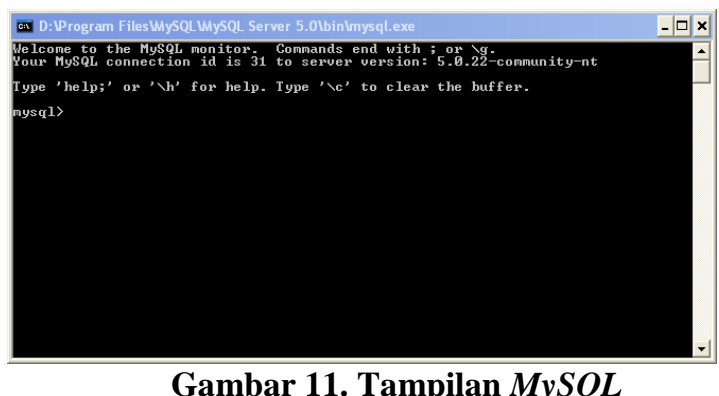

4. Topologi Star

Topologi star merupakan topologi yang menghubungkan beberapa komputer dengan menggunakan perangkat yaitu $h u b$ atau switch. Perangkat ini berfungsi sebagai pengontrol dari semua komputer yang terhubung dalam jaringan (Madcoms, 2004).

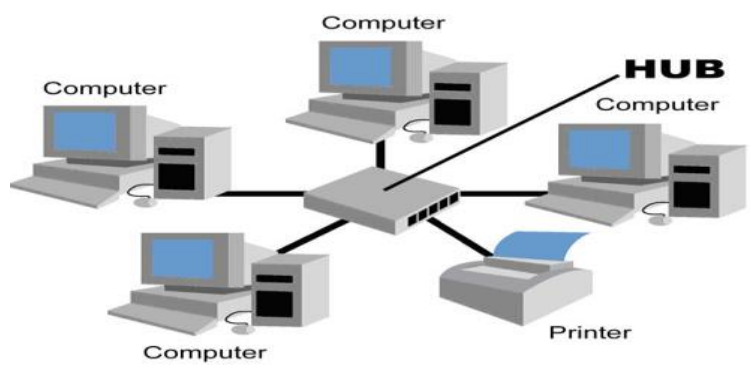

Gambar 12. Topologi Star

5. Client-Server

Server adalah komputer yang menyediakan fasilitas bagi komputer-komputer lain didalam jaringan dan Client adalah komputer-komputer yang menerima atau 
menggunakan fasilitas yang disediakan oleh server. Server di jaringan tipe Client-server disebut Dedicated Server karena murni berperan sebagai server yang menyediakan fasilitas kepada workstation dan server tersebut tidak dapat berperan sebagai workstation. Gambaran dari Jaringan Client Server dapat dilihat pada gambar 13 (Madcoms, 2004)

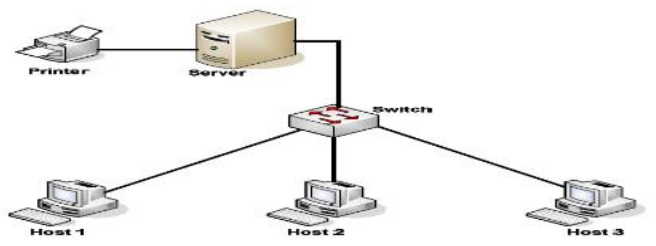

Gambar 13. Arsitektur Client - Server

\section{Kabel Cross}

Kabel cross adalah kabel yang memiliki urutan warna yang berbeda pada kedua ujung konektor, susunan mana saja yang membedakan nya ? dari susunan warna yang telah anda susun anda hanya tinggal menukar urutan pin/warna di salah satu ujung konektor yang anda pasang dimana urutan warna yang ditukar adalah urutan ke 1 dengan yang ke 3 dan urutan warna yang ke 2 dengan yang ke 6 . ( 1,3 ) (2,6), Maka hasilnya seperti berikut :

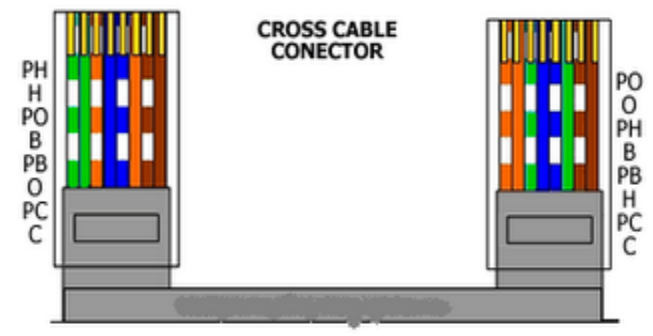

Gambar 14. Cross Cable Connector

Adapun fungsi dari tiap pin bisa dilihat pada gambar berikut :

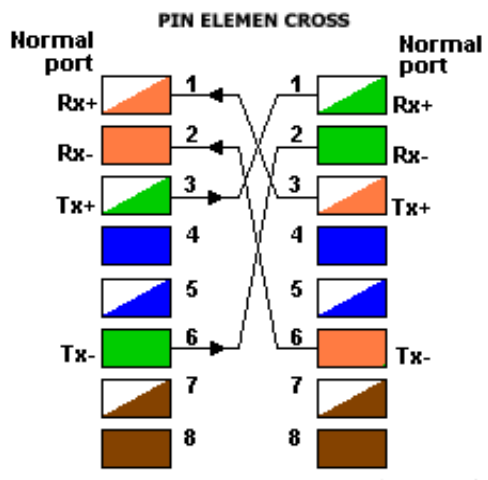

Gambar 15. Simbol Pin Element Cross

\section{7. $H u b$}

Suatu perangkat yang memiliki banyak port yang akan menghubungkan beberapa node (komputer) sehingga membentuk suatu jaringan pada topologi star (Fandimin, 2012).

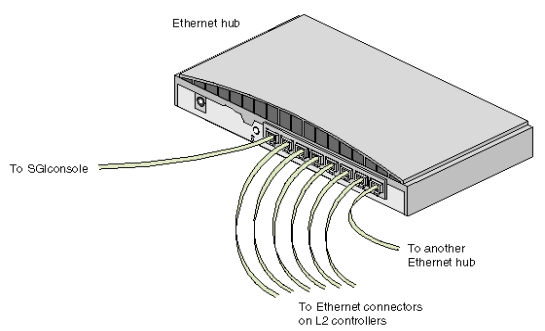

Gambar 11. Hub

\section{KESIMPULAN}

Dari permasalahan yang ada penulis memberikan kesimpulan mengenai program Sistem Informasi Koperasi Karyawan PT. Anugerah Pharmindo Lestari sebagai berikut :

1. Diharapkan dengan program sistem informasi koperasi karyawan dapat memberikan informasi simpanan, pinjaman, anggota dengan cepat

2. Didapatkan data yang akurat dan ter-backup dengan baik karena seluruh transaksi tersimpan dalam database yang terkomputerisasi.

3. Diharapkan sistem yang dibuat dapat diimplementasikan dan sekaligus dapat membantu dan berkontribusi secara aktif dalam peningkatan pelayanan.

4. Diharapkan dengan program yang telah dibuat dapat menghitung SHU anggota dengan cepat. 


\section{SARAN}

Untuk kelancaran sistem ini penulis memberikan saran yang sekiranya dapat membantu kinerja program Sistem Informasi Koperasi Karyawan "PT. A P L" Samarinda adalah sebagai berikut:

1. Melakukan penambahan sistem supaya anggota yang belum bisa membayar angsuran pada bulan yang sudah ditentukan bisa dikurangi dari jumlah saldo simpanan anggota tersebut.

2. Ditambahkan metode sms gateway sehingga jika ada anggota yang sedang melakukan perjalanan bisa melakukan pengecekan saldo dan juga jumlah sisa angsuran yang harus dibayar.

3. Bagi peneliti yang berminat untuk mengembangkan penelitian ini lebih lanjut agar dapat menambahkan fasilitas untuk pemberian suku bunga koperasi berdasarkan pinjaman, misalkan pinjaman $<=\mathrm{Rp}$ 10.000.000 maka bunga pinjaman sebesar $8 \%$ dan jika pinjaman >= Rp 10.000 .000 maka bunga pinjaman sebesar 20\% ( Tanpa Agunan / Jaminan.

4. Jika dalam proses peminjaman terdapat penggunaan agunan / jaminan maka bunga pinjaman akan menyesuaikan dengan suku bunga bank.

5. Bagi mahasiswa yang ingin mengembangkan program ini lebih lanjut diharapkan untuk menambahkan laporan anggota koperasi secara mendetail dan menyeluruh.

\section{DAFTAR PUSTAKA}

Alam, M. Agus J. 2005. Cara Mudah Menggunakan Crystal Report XI, Jakarta : Elex Media Komputindo

Jogiyanto,HM. 2005. Analisis Sistem Informasi Pendekatan Terstruktur Teori dan Praktek Aplikasi Bisnis, Jakarta

Janner, Simamarta, 2010, Rekayasa Perangkat Lunak, Yogyakarta: Penerbit Andi.

Kadir Abdul, 2008. Tuntunan Praktis Belajar Database Menggunakan MySQL, Penerbit : Andi Offset

Lughot, 2011, Kabel Jaringan Straight and Cross, http://lughot.blogspot.com/2011/04/kabel-jaringanutp-straight-dan-cross.html\#ixzz20g6DTli0, diakses pada tanggal 03 Oktober 2012

Mangkulo, Hengky Alexander, (2003), Aplikasi Database Menggunakan ADO VB 6.0 dan SQL Server 2000, Surabaya : Elex Media Komputindo

Madcoms, 2004, Sistem Jaringan Komputer Untuk Pemula,Penerbit : Andi Offset

Rahadian Hadi,2003. Membuat Laporan dengan Crystal Report 8.5 dan Visual Basic 6.0,Bandung : Elex Media Komputindo 